\title{
ESTÉTICA Y POLITICA EN EL PENSAMIENTO DE CARLOS MARIA DE BUSTAMANTE
}

\section{Por Ernesto Lemoine}

Hipólito Taine afirmaba a fines del siglo pasado que "para comprender una obra de arte, un artista, un grupo de artistas, es preciso conocer con exactitud el estado general del espíritu y de las costumbres de los tiempos a que ellos pertenecen". Juicio que reforzaba con otro iguatmente valedero: "Del mismo modo que existe una temperatura física que, por sus variaciones, determina la aparición de tal o cual especie de plantas, así también existe una temperatura moral que, por sus variaciones, determina la aparición de tal o cual especie de arte." 1 O sea, en palabras de un crítico de nuestros días, que "el mundo del arte y de la estética no se produce aisladamente, ni de la cultura a que pertenece ni de su tiempo histórico". 2

Ahora bien, dentro de esa "temperatura moral" que dice Taine, o "tiempo histórico" que precisa Fernández, consideramos que uno de los aspectos más interesantes de la estética es el examen de las relaciones o conexiones entre el arte (en sus formas y en sus ideas) y el pensamiento político de una época determinada. Arte y política no son dos esferas del quehacer humano que se den la espalda. Es más, se condicionan de tal modo, que el primero no podria explicarse a plenitud ignorando el contexto de la segunda, y ésta, a su vez, se capta mejor si entre la diversidad de fuentes que la alimentan no desestimamos el momento artístico que le es sincrónico.

Lo arriba expuesto es premisa necesaria para entender un aspecto fundamental de lo mexicano como expresión ontológica: la evolución de su arte -y de su crítica artística- al compás de su desarrollo históricopolítico. Vemos así, en apretado resumen, que el arte antiguo detiene su vuelo, brusca y tajantemente, con la Conquista; y sus eplgonos, aunados a la peculiar sensibilidad del artesano indigena, se incorporan, bien que con timidez y casi a hurtadillas, a los estilos artísticos dispuestos -impuestos- por los europeos: verbigracia, el llamado "tequitqui" por Moreno Villa, en las fachadas e interiores de gran número de iglesias y conventos del siglo xvi. Lo nuevo, a partir de 1521, es, naturalmente, el

1 Filosofia del arte, México, Editorial Nueva España, S. A., 1944, pp. 6 y 8.

2 Justino Fernández, El Hombre. Estética del arte moderno y contempord́neo, México, UNAM, 1962, p. 12. 
arte occidental, que a lo largo de tres siglos va discurriendo por los mismos cauces y modas que estatuye la metrópoli. Y Nueva España, que en su realidad geoestética principia por ser un país renacentista, con no pocos resabios medievales, concluye su periplo en franco neoclasicismo, luego de disfrutar y renegar de su largo y esplendoroso ciclo barroco. El último cambio es el que nos interesa, porque en él se incrustan las ideas del personaje objeto de nuestro estudio.

El tránsito de lo barroco a lo neoclásico, aparte de significar la irrupción de una moda -se ha dicho muchas veces-, coincide con una mudanza radical en la forma de ser y de pensar de la sociedad colonial. Mundanza que culminará en la independencia de 1821, después de haber pasado por una larga etapa de revolución intelectual (últimas décadas del siglo xvin y primera del xix) y una más breve de revolución política (1810-1821). Aunque el término "revolución intelectual" parece excesivo, pues España y sus colonias pusieron un fuerte dique a la difusión de las ideas de los pafses más adelantados (por ejemplo, no sólo Rousseau, Voltaire y demás progresistas franceses fueron inscritos en el index, sino que se prohibió la edición en castellano de la Historia de Clavijero y la lectura de los Comentarios Reales del Inca Garcilaso, obra autorizada y publicada desde principios del siglo Xvis), sí puede hablarse de una "renovación espiritual" y de una "modernidad", discretas y siempre a la zaga de Europa, y menos latas de lo que suponen algunos eruditos, como Méndez Plancarte y Bernabé Navarro. Y dentro de esa corriente renovadora, uno de sus reflejos más sugestivos atañe al arte y a la crítica de arte; sobre todo la segunda, que empieza a moverse sobre bases extraestéticas, como una forma sutil de camuflar una cierta postura sociopolitica que tendía a poner en entredicho las bondades del sistema establecido.

La dialéctica finisecular se entabla entre el "arte viejo" y el "arte nuevo", o sea, entre el barroco y el neoclásico. Aunque los especialistas de nuestro tiempo han sostenido la tesis, que ha creado opinión, de que el barroco - $y$, más aún, lo llamado "ultrabarroco"- es la forma de expresión más genuinamente mexicana, cabe objetar que en otras épocas la crítica de arte ha opinado de manera diversa. Por ejemplo, entre fines del xvin y principios del xix, los criollos neoclásicos e ilustrados dijeron, punto menos, que el barroco, ese "arte degenerado", no podía representar la mexicanidad, pues era un fiel reflejo de la esclavitud (mental) del país y de la omnipotencia peninsular; mientras que las formas neoclásicas y académicas, sencillas, equilibradas y limpias de 
"retorcimientos y hojarascas", significaban la liberación del individuo y de la sociedad, la "nacionalización" del arte, la expresión de un cspíritu no peninsular.

Esta tesis, que fue la que siguió Bustamante, es la que interesa a nuestro tema. Desde luego, salta a la vista la falacia que encierra, derivada del hecho de calificar una modalidad artística con una regla no ortodóxamente estética, sino más bien sociopolftica. $\mathrm{E}$ incluso, decle este punto de vista, juzgadas las cosas por parejo, el barroco y el neoclásico eran tan "opresivamente españoles" como todo el sistema colonial; la Academia, ideada y regida por peninsulares, no era más que un instituto similar a sus congéneres de la metrópoli; y, al último, el derroche "inútil" y el "ofensivo" dispendio que se cargaban en la cuenta de las grandes construcciones barrocas y churriguerescas, en nada era inferior a lo que luego se vio con los edificios neoclásicos, como los muy costosos del Palacio de Minería y la iglesia de Loreto, monumentales y todo pero ya amenazando ruina desde antes de su conclusión. Tampoco reparaban los académicos ( $y$ en especial los de origen criollo) en que si no era signo de mexicanidad el estilo barroco, mucho menos podia serlo el neoclásico, identificado como pocos con la estirpe más remota y pura del arte occidental. Visto a distancia el problema, con la serena perspectiva de siglo y medio de experiencias y meditaciones, de cuál cs menos y cuál es más mexicano, Justino Fernández da con la clave más afortunada:

Si en verdad México es esencialmente barroco, como dicen, entonces con el neoclásico y lo que significa se abrió un paréntesis en nuestro ser que aún no parece haberse cerrado. Pero esto resulta absurdo; más real es considerar que México es tan complejo y vigoroso como para cambiar su destino y que ha podido seguir siendo de otros modos... Vistos asi los dos momentos (el barroco y el neoclásico), cada uno en su tiempo, no existe n1 suspensión de ser, ni falsificación de ser, sino modos de ser siendo. ${ }^{3}$

Exacto; pero en la época en que se opera el cambio de gusto estético, no se pudo (o hubo intencionalidad en no hacerlo) llegar a esta correcta y serena interpretación.

Porque los ilustrados novohispanos, repetimos, en su búsqueda de apoyos doctrinarios para justificar la existencia del ente nacional, echaban mano de cualquier recurso indirecto que, sin colocarlos de plano frente a la autoridad oficial, les permitía socavar, lenta y disimulada-

8 Véase, El arte del siglo XIX en México, UNAM, I967, p. 5. 
mente, las bases materiales y morales en que se sustentaba el antiguo régimen. Y la crítica de arte fue uno de esos recursos, pues la apología de lo neoclásico y la revaloración de lo prehispánico, junto con el ataque despiadado a todo lo que oliera a barroco, significó, bien que forzando al máximo su verdadero contexto, una de las formas de repudio a las instituciones coloniales.

Granados, el autor de Tardes americanas (que al morir dejó inconclusas unas Tardes mexicanas) y Fernández de Lizardi, entre otros, son algunos de los pensadores destacados que sostuvieron tal tesis de marcado sabor nacionalista. ${ }^{4} \mathrm{Y}$ en esa línea se inscribe también el controvertido escritor y político oaxaqueño Carlos María de Bustamante, del que poco se sabe que gustara ocuparse de la crítica de arte. Reunimos en este trabajo unas cuantas de sus ideas en ese campo, no sin antes advertir que todas ellas fueron expuestas más por un prejuicio sociopolítico que por un interés puramente estético. Pero, justo en ello radica su importancia.

Carlos María de Bustamante, hijo de padre español y madre criolla, nació en la ciudad de Oaxaca en 1774 y murió en la capital de la República en 1848. Vivió, por lo tanto, casi tres cuartos de siglo: tiempo esencialmente de crisis y de fluctuaciones; encrucijada entre dos eras y dos estilos de vida; tránsito de un mundo que dejaba de ser lo que había sido y no conseguía llegar a lo que soñaba con ser; la pesadilla y la esperanza, de la Colonia a la Independencia, de la Nueva España a La República Mexicana: tal fue el sino que condicionó la existencia de Bustamante y la de todos aquellos que, nacidos durante el reinado de Carlos III, "cuando España inicia la fase quizá más sana y equilibrada de toda su historia", " se van muriendo en las proximidades de 1847. "el annus terribilis que, llevando en su seno el primer choque con el extranjero, arrojo al país al borde del colapso". ${ }^{8}$

Testigo y protagonista notable de su época, Bustamante fue, por sobre cualquiera otra actividad, escritor; de obra tan pasmosa por su

4 Véase el certero juicio que de Granados hace Justino Fernández en: El Retablo de los Reyes. Estética del arte de la Nueva España, UNAM, 1959, pp. 75-79. También la espléndida edición que de las Obras de Lizardi viene publicando, desde 1963, nuestra Universidad.

6 Prólogo de Julián Marias a: Gaspar Melchor de Jovellanos, Diarios, Madrid, Alianza Editorial, 1967, p. 8.

G Ralph Roeder, Juárez y su México, México, 1952, s.i., t. I, p. 320. 
volumen, que se ha hecho proverbial citar "su desmedido afán de hacer sudar las prensas" (Icazbalceta). Desigual en grado superlativo, erudito anárquico, arbitrario y apasionado, "ajonjoll de todos los moles" y, para no alargar la lista, irreflexivo y atropellado en la mayoría de sus textos impresos; posee, empero, dos virtudes que lo han salvado del olvido póstumo: su innegable patriotismo, y su franqueza y valor cívico para expresar, sin tapujos, lo que él creía ser su verdad. No importa que en ello a menudo se equivocara, o que perdiera la compostura y la proporción de las medidas, pues por encima de sus defectos - comunes a toda su generación-, emergió la sinceridad de su pensamiento, cuyo estudio es imprescindible para conocer la realidad dramática del primer medio siglo de vida independiente mexicana.

A partir de 1812, cuando rompe en definitiva con el sistema bajo el cual había nacido y se habia educado, se entrega a la tarea de fustigar con furia no disimulada al sistema virreinal, oponiéndole la visión id́lica del mundo prehispánico y la gesta heroica de la insurgencia, como otras tantas instancias históricas que, por mexicanas, harían polvo hasta el recuerdo de tres siglos de coloniaje. Bajo tal compulsión anímica redacta, entre 1821 y 1827 , su obra más importante y afamada, el Cuadro histórico de la revolución de independencia, que en última instancia no es más que su alegato de defensa de la mexicanidad y de condena de la Colonia. Después, con la amargura y desilusión que le produjeron la anarquía y el desgobierno de la etapa republicana, refrenarfa algo su hispanofobia; aunque, hasta el final de sus días, jamás dejaría de hablar de las "horribles crueldades de los conquistadores de México", que subyugaron a los pueblos indígenas, "acabaron con toda su nobleza, destruyeron su religión, sus templos, edificios y monumentos, sus bibliotecas $y$ archivos $(y)$ sacrificaron millones de sus habitantes". ?

Pero Bustamante fue un autor polifacético al que se le ha hecho poca justicia encasillándolo sólo como "apologista de los indios y de la insur. gencia y detractor de los españoles". Le interesaron y abordó muchos temas y aspectos de la vida y el intelecto. Por ejemplo, su historia de la Virgen de los Remedios, era una de las lecturas predilectas de un crítico suyo tan exigentísimo como Alamán. Escribió sobre vulcanología y terremotos; fue un agudo y chispeante autor costumbrista, en nada inferior a Fernández de Lizardi o a Guillermo Prieto; un cronista, motu

T Tal escribió en la última obra que publicó (1847): El nuevo Bernal Diaz del Castillo, o sea, historia de la invación de los anglo-americanos en México. Citamos por la edición de la Secretaría de Educación Pública, México, 1949, t. 1, p. 113. 
proprio, de la ciudad de México, al que nunca se cita como tal; y, en fin, lo que aquí nos interesa, ensayó la crítica de arte, desde su perspectiva de intelectual comprometido con una determinada postura ideológica.

Fundador, con Jacobo de Villaurrutia, del Diario de México, que en la historia de nuestras letras es la primera publicación cotidiana de trascendencia, Bustamante empieza a insertar ahí, desde octubre de 1805, artículos del más variado jaez: notas necrológicas, traducciones, textos literarios, critica social, urbanismo, asuntos culturales, historia antigua de México, cuestiones arqueológicas y etnográficas, económicas y estadísticas, etcétera. Cabe agregar, por supuesto, que entre esa abigarrada miscelánea, no son desdeñables sus noticias y opiniones que, directa o indirectamente, se refieren al arte en general o a una determinada obra artística en particular.

Es de sentirse que la inteligente $y$ acuciosa investigadora Ida Rodriguez Prampolini, al elaborar su importantísima obra, La critica de arte en México en el siglo xix, hubiera pasado tan de prisa por las páginas del Diario de México, donde habria hallado una preciosa mina de materiales para su libro. Pocos son los textos que recoge de ese valioso cotidiano, y uno de ellos es precisamente de Bustamante, pero la autora no lo identifica por haber estado suscrito con iniciales. ${ }^{8}$ Por su parte, el doctor Fernández hace una breve pero aguda alusión a don Carlos María, a propósito de un juicio de éste, recogido por González Obregón, en defensa del gusto por la estatuaria grecolatina que mostraba la sociedad novohispana de 1810: "Así -dice Fernández-, consciente o inconscientemente se expresaba un nuevo espíritu que encontró en la reinstauración del clasicismo su señal o estandarte." ' Fuera de estas dos autoridades, no hemos encontrado a ninguna otra contemporánea que cite a Bustamante como crítico de arte. A ambas nos unimos nosotros en esta ocasión.

El oaxaqueño, obvio es decirlo, se afilia sin reservas a la corriente "neoaztequista", que con Granados, Alzate, Lcón y Gama, el padre Márquez y hasta el mismo Humboldt, aparte del belicoso fray Servando, intenta revalorar las categorías pensantes y artísticas del mundo pre-

8 Véase el t. I, p. 22. El texto de Bustamante, que apareció en el Diario de México de 18 de marzo de 1810 , bajo las iniciales "C. M." y con el título "Arquitectura de Moctezuma", lo transcribe la doctora Rodríguez Prampolini a pp. 174-176. Edición UNAM, 1964.

${ }^{\circ}$ El arte del siglo $\mathrm{XIX}$ en México, p. 11. 
hispánico. Corriente que, incluso, llegó a contar con el beneplácito oficial, pues es por esos años (principios del siglo XIX) cuando Iturrigaray patrocina los viajes arqueológicos de Dupaix, uno de cuyos dibujantes, Castañeda, trabajaría cinco lustros después con el propio Bustamante en un romántico programa de exploraciones arqueológicas en la comarca de Texcoco. ${ }^{10}$

No nos ocuparemos aquí de sus empeños reivindicatorios "neoaztequistas", que dan tela para un amplio estudio, sino de sus opiniones en torno a otra postura "neo": la clásica. Lector fanático, aunque desordenado, de la literatura grecolatina, al grado de traducir y divulgar entre el público mexicano a Virgilio, " Bustamante, cuyo espíritu siempre se nos ha figurado tan retorcido como una columna salomónica, es, sin embargo, un fervoroso admirador de Vignola y Vitrubio, un arresivo Quijote, lanza en ristre contra los molinos de viento barrocos, y un apologista gozoso de lo neoclásico, como lo fueron en su tiempo y en la Península, Jovellanos, Campomanes y Ponz. No nos sorprende, en consecuencia, el entusiasmo con que habla de la creación de la Academia de San Carlos novohispana. Así, en una obra escrita hacia 1836, al elogiar la colección de vaciados que había traído Tolsá, el autor no desaprovecha la oportunidad para insistir en lo meritorio del talento artístico nativo.

A la verdad -afirma-, México no necesitaba entonces más que de estos bellos modelos, pues tenfa en su seno excelentes profesores. principalmente de pintura, como puede conocerlo el que compare las obras del día con las del siglo pasado. Florecia entonces el famoso Gerónimo Gil, venido años

10 Véanse nuestras ediciones a dos curiosas obras de Bustamante: Memoria estadistica de Oaxaca y descripción del valle del mismo nombre, México, Secretaría del Patrimonio Nacional, 1963; y Tezcoco en los últimos tiempos de sus antiguos reyes, México, Biblioteca Enciclopédica del Estado de Mexico, 1970.

11 El exigente y autorizado humanista Pedro Henriquez Ureña, nada sospechoso de congeniar con la figura y la obra de Bustamante, nos ha dejado, sin embargo, un juicio menos acre de lo que podía esperarse de él, sobre la traducción que de la Eneida hizo el oaxaqueño: "Claro es que esta versión para escolares, hecha durante un receso de labores legislativas, apenas puede ser tomada en cuenta como trabajo literario: toda ella es infiel y redundante, plagada de errores fáciles de comprobar... Pero nunca cs en vano el trato con los grandes maestros; y Bustamante, de suyo escritor incorrecto y desordenado, aunque pintoresco y con sus puntas de imitador de Cervantes, logra en esta versión cierta dignidad de estilo que, si todaría queda muy lejos de Virgilio, está por encima de la forma usual en el autor del Cuadro historico. Hay en ella, sobre todo, un vago sabor arcaico que hace agradable la prosa considerada en sí misma." En: Traducciones y paráfrasis en la literatura mexicana de la época de Independencia, México, Imprenta del Museo Nacional, 1913, p. 5. 
antes de Europa, y tan sobresaliente en su facultad, que de la corte se le mandaron grabar las medallas de la Academia del Derecho Público de Madrid, y las que se remitieron a Manila de orden del rey, trabajadas en nuestra Casa de Moneda para aquella Sociedad de Filjpinas. 12

La admiración de Bustamante por Gil y la Academia, venía de muy atrás; y no es aventurado apuntar que a él se deba la nota necrológica que apareció en la Gazeta de México (21 de mayo de 1798), dando cuenta de la muerte del ilustre grabador, "cuyo nombre -leemos en ella-fijará la época del buen gusto que se lleve en el aprecio y cultivo de las Artes".

Recordemos que Bustamante vino de su nativa Oaxaca a la capital, en 1794, para seguir aquí la carrera de jurisprudencia. Salvo breves ausencias (como un viaje a Guanajuato en 1800 , donde conoce a Hidalgo, y otro a Guadalajara, para recibirse ahi de abogado), no abandona ya la metrópoli sino hasta fines de 1812 , cuando decide incorporarse a la revolución acaudillada por Morelos; y retorna hasta octubre de 1821, cuando la independencia se ha consumado. Le toca, pues, presenciar, todo el progreso edilicio de la ciudad de México en las dos últimas décadas de la paz octaviana virreinal. Progreso que coincide con el auge de la Academia, con el éxito y la fama de Tolsá y su escuela, con la furia antibarroca' y la prepotencia del espiritu neoclásico. $Y$, demás está decir, don Carlos se afilia gustoso a tan singular boom estético y constructivo.

En su tarea de coeditor del Diario de México, Bustamante no es ajeno a la inserción de textos tomados de publicaciones europeas, que, al amparo de plumas mundialmente reconocidas, sustentan y divulgan el credo estético neoclasicista: prueba del gusto imperante, y en particular del de nuestro personaje. Tres ejemplos son ilustrativos: en los números de 19,3 y 4 de marzo, aparece el siguiente artículo: "¿Son superiores las bellas letras a las bellas artes? Alegoría por Mr. Klopstok"; y otro más largo, de Lessing, los días 12 y 13 de marzo y 6 y 7 de abril: "Sobre la comedia"; 13 por último, en los números de 10 y 11 de abril de 1809 , se insertó el "Discurso por Mr. Winckelman sobre el estilo sublime y del

12 Carlos Maria de Bustamante, "Suplemento" a la obra del padre Andrés Cavo, Los tres siglos de Méjico, Méjico, Imprenta de J. R. Navarro Editor, 1852, pp. 170 171. (La primera edición, 1836-38, consta de 4 vols.)

18 Para asomarse al Lessing dramaturgo, una fuente accesible es la edición del Laocoonte, con introducción de Justino Fernández, México, UNAM ("Nuestros Clásicos" 16), 1960, pp. VII-VIII. 
dibujo entre los griegos". ${ }^{16} \mathrm{Y}$ estos artículos los entremezclaba Bustamante con otros sobre temas prehispánicos: historia, literatura, arte. Agreguemos, de paso, que por esos años y para ayudar con su grano de arena en la lucha del pueblo español contra los ejércitos de Bonaparte, don Carlos, autorizado por el bondadoso arzobispo-virrey Lizana, mandó troquelar una medalla con la efigie de Fernando VII (en tres corizaciones: cobre, plata y oro), el producto de cuya venta destinaba como donativo para los patriotas peninsulares; pues bien, el dibujo del grabado de dicha medalla, se 10 encomendó al conocido artista Tomás de Suria, ${ }^{15}$

Pero su querencia máxima era Tolsá; lo elogia con vivo entusiasmo, aunque en ocasiones, por motivos extra-artísticos, censure algunos detalles de sus obras. En particular le atrajo, y no podía ser menos, la estatua ecuestre de Carlos IV. En una antología del famoso Cabaliito, fácil de componer, pues abundan preciosos materiales para ello, el nombre de Bustamante no podría quedar fuera. Nuestro personaje fue testigo presencial en las ceremonias inaugurales de los dos monumentos: el provisional (1796) y el definitivo (1803), por lo que sus comentarios son dignos de apreciarse. $Y$ adelantemos el juicio concluyente del crítico oaxaqueño: admira la estatua como una insigne obra de arte (criterio estético), pero la rechaza, indignado, por lo que simboliza (criterio político). Oigámoslo:

Al observar el monumento provisional que, como se sabe, fue hecho en madera, opina que la estatua "era magnifica y obra maestra de escultura", lamentando que el caballo pisara con la pata izquierda "el

14 El doctor Juan A. Ortega y Medina, en su erudito y esclarecedor estudio sobre Winckelmann, se duele, y con sobrada razón, de que la obra del esteta alemán permaneciera casi ignorada para los lectores de lengua castellana. "Nuestra penuria es increible y vergonzosa" -concluye. El dato que aportamos, seguramente habría mitigađo, bien que en pequeña dosis, su justo clamor. Pero lo curioso -y es el mismo doctor Ortega quien nos pone sobre la pista- es que el articulo del Diario de México está copiado literalmente de Ja publicación madrileña Espiritu de los mejores diarios literarios que se publican en Europa, numero del 23 de agosto de 1790, jcon casi veinte años de retrasol Como dato curioso, este Espititu.... del que poscemos un volumen, era una especie de Reader's Digest espańol, que reproducia textos de otras naciones, también con bastante retraso. "Casi medio siglo hubo de transcurrir, a partir de su fuente original, para que, por Bustamante, los novohispanos conocieran un escrito breve de Winckelmannl Véase: J. J. Winckelmann, De la belleza en el arte clásico. Selección de estudios y cartas. Traducción del alemán, prólogo, notas y apéndices de Juan A. Ortega y Medina, México, UNAM, 1959, p. 60.

16 El convite de suscripción fue anunciado en el Diario de México, 20 de octubre de 1809 . 
águila y carcax, blasón de nuestro antiguo imperio", pues con ello no se hacía sino irritar "a una nación digna de otra suerte". Con motivo de la colocación de dicha estatua provisional, es muy conocido, la Plaza Mayor de México fue remodelada, quedando en la forma que nos es familiar por el excelente grabado de Fabregat, sobre un dibujo no muy fiel de Jimeno y Planes. Aunque algunos autores, uno de ellos Tous:aint, afirman, con el solo apoyo del grabado de Fabregat, que nunca 1a Plaza ha presentado un aspecto más digno y hermoso que el que le dio la reforma de 1796, Bustamante fue de otra opinión: "El terreno destinado para colocar la estatua, se elevó cuatro pies y medio, y se le rodeó con un muro ataluzado de igual altura, terminado con un filete y una gran faja plana de poco vuelo. Con este cerco quedó inutilizada y desfigurada la hermosa Plaza Mayor de México, mereciendo una desaprobación general." 10 Quizá lo que le chocaba, era ver a Carlos IV tan destacadamente enmarcado; el caso es que, cuando en 1822 la gran plaza fue liberada de ese cerco neoclásico, tal y como se ve en la interesante vista de D'alvimar, Bustamante aplaudió gozoso la medida. E hizo algo más. Como se sabe, la modificación de la Plaza se hizo por etapas: primero se encapuchó a Carlos IV "para que su vista no siguiera ofendiendo al pueblo mexicano", luego se demolió la balaustrada con todos sus accesorios, más tarde se quitaron las cuatro fuentes, y al último fue retirada la estatua, para llevarla al patio de la Universidad. Pues bien, antes de que se realizara la tercera etapa, ya Bustamante, por medio de la prensa, sugería:

Yo arrasaria las cuatro fuentes que rodean la Plaza de Armas de México, y en las que no corre agua y son un receptáculo de inmundicias: en estos lugares levantaría cuatro columnas que consagraría a los señores Hidalgo, Allende, Morelos y Mina; truncarialas en señal de que comenzaron la obra de nuestra libertad sin concluirla. 17

Aquí está la génesis de ese imposible monumento a la Independencia, que lustros después se encomendaría a Lorenzo de la Hidalga y que nunca se llevaría a cabo.

16 "Suplemento" a Los tres siglos de Méjico, p. 221. "Arreglada asi esta plaza -escribe Manuel Toussaint-, con la imponente catedral en el fondo, el palacio de los virreyes de un lado, el del Cabildo en el otro, era digna de figurar entre las plazas más bellas del mundo." Mas, parece que el adorno (balaustrada y talud), aunque digno desde el punto de vista arquitectónico, era muy estorboso. Véase: Arte colonial en México, México, UNAM, 1962, p. 223.

17 La Abispa de Chilpancingo, México, mayo de 1822, núm. 17. 
Respecto a la estatua definitiva, don Carlos nos proporciona más de un dato curioso "de este prodigio", que por "haber sido fundida de una pieza y de un lance, es uno de los más preciosos monumentos de las artes". Afirma que ya desde la inauguración de la provisional, la gente la citaba como "el caballito": reacción subconsciente de la importancia que le daba a la bestia sobre el jinete. Jerarquia en que también concordaba el crítico, enfatizándola con su pizca de nacionalismo, como lo prueba este aserto:

Dos caballos mexicanos sirvieron de modelo para la construcción del de la estatua; para la provisional, uno de la raza del marqués del Jaral en San Luis Potosí, y para la de bronce uno de Puebla. La raza mexicana nada tiene que envidiar a la de Andalucía, de donde la trajeron los españoles, y quizá ha mejorado en este clima. ${ }^{18}$

Lo arriba transcrito era el pensar de Bustamante dicho con calma y en una época, la nacional, en que ya ningún riesgo corría por externar opiniones antiespañolas. Pero en tiempos más peligrosos para él, o sea, en pleno régimen virreinal, se aventuraba en hacer públicos sus reparos, más que a la estética del monumento, al insufrible carácter sociopolítico que manifestaba. Así, en un remitido suyo que publicó el Diario de México el 16 de diciembre de 1805, bajo el prudente seudónimo de "El Toticoniche", aludiendo a "la mayor estatua que ha tenido la América y que no posee igual la Europa", se ocupa de la inscripcióin que en letras de bronce figuraba en una de las caras del pedestal: Mexicanus. Populus. Corda. In. Fornacem. Mittens. Caroli IV. Statuam. Fudit; e, indignado, comenta:

Quiere decir... que habiendo echado el pueblo mexicano sus corazones... en un horno, fundió (esto es, hizo de fundidor) la estatua ecuestre de Carlos IV. ¿Qué bagatela! QQué patraña! Por tanto, el pueblo de México está descorazonado, porque echó sus corazones en una hornada... ICamaradal ¿Y a esto se llama inscripción?... Cuando el escritor razona, debe hacerlo con claridad; cuando describe, con hermosura, y cuando refiere, con llaneza y sencillez. Este mamarracho no la tíene: es una alegoría formada con violencia, inverosimilitud y ridiculez...

Y sigue despotricando, auxiliado por sus clásicos (Homero, Cicerón, Bossuet y hasta Cervantes), contra el texto de la ofensiva placa. Mas, ya se advierte, su impugnación no se debe, aunque así lo aparente, a la

18 "Suplemento" a Los tres siglos de Mejico, p. 237. 
forma sino al fondo de la inscripción, pues le resulta intolerable que se diga que el pueblo mexicano ofrendó su corazón para hacer realidad tan soberbio homenaje a Carlos IV, que sólo debe cargarse a la cuenta del venal virrey Branciforte.

Testigo de los dos majestuosos ascensos del Caballito (el de 1796 y el de 1803), Bustamante lo será también de la dramática caída del inás famoso, el de bronce. Diputado al Congreso desde 1822, sus vitriólicos discursos contra el pasado inmediato son yesca que aviva el fuego de la hispanofobia. Algunos de sus colegas, incluso más radicales que él, exigen la destrucción de la estatua y la del mausoleo de Hernán Cortés, también obra de Tolsá, erigido en el Hospital de Jesús. Consiguen esto último; y en cuanto a lo primero, voces sensatas logran que la estatua sea retirada de la Plaza Mayor y guardada en el patio de la Universidad "como obra de arte", que, en última instancia, tal era su valor fundamental.

Observador curioso, irónico y chispeante, don Carlos nos ha dejado un simpático relato del descenso del Caballito de su airoso pedestal, y de su lento y triste cabalgar hacia el recinto universitario. En su Diario comenta varias veces el suceso. Registro del $1^{9}$ de junio de 1824:

Hoy han estado bregando en la Plaza para remover la estatua ecuestre y apenas la han podido levantar media vara. |Válgame Dios por Borbones que aun en estatua nos han de ser molestosl La incomodidad ha de continuar por algunos dias, pues ha llovido extraordinariamente y los cables casi se han inutilizado con los aparejos de la máquina.

Registro del día 3: "Sigue la estatua ecuestre bajando. La boca del caballo está hoy besando con el borde del pedestal. En la noche se ha trabajado y no poco. Su magestad de bronce ha manifestado que estaba gustoso enseñoreándose desde allí de la Nueva España." $\mathrm{Y}$ el día 5 anota:

Por fin ha bajado hoy a tierra la estatua de Carlos IV y con hechos ha mostrado el ingeniero su habilidad. Me aseguran que una mano maligna clavó unos muy gruesos clavos a los molinetes que impedian la rotación, y que se busca al malvado autor de esta fechoría; y que hasta que se notó el yerro o defecto no pudo realizarse la operación. Se trasladará al patio de la Universidad, lugar a propósito para conservar este admirable monumento de las artes. 19

19 El Diario histórico de Bustamante, en su mayor parte inédito, es una rica mina de informaciones sobre la vida mexicana de la primera mitad del siglo xix. El origi- 
Finalmente, en sus adiciones a la Historia del padre Cavo, recordando la erección de 1803 "y el modo [con] que se condujo la estatua a la Plaza Mayor y se colocó en ella en el breve espacio de siete minutos a la altura de diez varas", agrega:

Yo presencié este acto, y me admiré de la facilidad con que se ejecutó esta operación; aunque mucha mayor me causó el modo sencillisimo con que después fue [trasladada] ... de la Plaza a la Universidad, donde hoy existe, pues por modo de juguete la llevaron unos muchachos sin el aparato que la vez pasada, debido todo a la sabiduría del ingeniero francés que se encomendó de conducirla. ${ }^{20}$

Por el tiempo en que Carlos IV abandonaba definitivamente la Plaza Mayor, Bustamante luchaba a brazo partido para que el gobierno patrocinara la erección de diversos monumentos dedicados a los mártires de la Independencia. Al fin consiguió que el Congreso del Estado de México le encomendara el de Morelos -su héroe predilecto-, que se alzaría en San Cristóbal Ecatepec. Y al respecto, apunta en su Diario del 5 de octubre de 1825:

Dicho monumento se formará de los fragmentos del pedestal de piedra villeria, que semeja al marmol blanco, de la base o pedestal de la estatua ecuestre de Carlos IV. No puede dársele destino más honroso. Los directores de esta obra son, por disposición del comisionado Bustamante [habla en tercera persona de si mismo], don José Agustín Paz y don Pedro Patiño [Ixtolinque], ambos directores de la Academia de San Carlos de México, el primero en el ramo de arquitectura y el segundo en el de escultura.

Además de ocuparse de la estatua ecuestre de Carlos IV, Bustamante comentó repetidas veces, a través del Diario de México, la obra arquitectónica de Tolsá; viajes que casi siempre aprovechaba para elogiar la sensibilidad estética de los indígenas, la irrupción del "buen gusto" neoclásico y el feliz destierro de "los peripatéticos, los púlpitos, los gerundios y los talleres [de] los Churrigueras". En una serie de artículos, donde se simula una polémica entre "El Melancólico" y "El Ex. D. P.", siendo don Carlos el primero de estos personajes ocultos bajo seudónimo (aunque sospechamos, por la similitud del estilo de uno y otro, que

nal se conserva en la ciudad de Zacatecas. Nosotros consultamos la copia microfilm que posee el Archivo Histórico del Instituto Nacional de Antropologia e Historia.

20 "Suplemento" a Los tres siglos de Méjico, p. 297. 
ambos correspondan al mismo Bustamante) se consigna el siguiente diálogo:

Los edificios públicos, que atraen necesariamente las miradas de un viajero, han exigido también las mías, con las que he pagado un tributo de admiración a los muchos que hay en esta hermosa ciudad. Mas ninguno ciertamente las merece con tanta justicia como el Seminario de la Mineria que se está concluyendo en la calle de San Andrés. La vez primera que lo vi, quedé sobrecogido de su magnificencia y belleza y del gusto y valentía del arquitecto que ha sabido trazar y ejecutar obra tan útil como elegante.

¿Quién es - pregunté a un hombre que tenía al lado- el director de esta obra?

El mismo -me respondió- que fundió la estatua del Rey que está en la Plaza de Palacio.

Fijé entonces más la vista en todo el edificio y exclamé con las mismas expresiones de asombro con que Agesilao, Rey de Esparta, elogió el valor y sabiduría de su enemigo Epaminondas cuando le iba a atacar:

¡Qué hombre! ¿Qué prodigio! ... TTan sabio en la escultura como en la arquitectura! TTan bien maneja el cincel como la escuadra! ¡Dichoso país que posee tal artffice y que conoce y respeta su méritol

Pasé después de esto a recorrer todas las oficinas de aquella casa y vi -dígolo con regocijo- que es la más digna morada de las ciencias, y que jamás se ha dado mejor destino a las riquezas de la América que gastándolas con generosidad en la erección de este Colegio.

Luego, los polemistas se enfrascan en una discusión acerca de las inscripciones que suelen ponerse en los edificios al tiempo de su inauguración. Y a una réplica del "Ex. D. P.", se encrespa el amor propio indigenista de "El Melancólico", o sea Bustamante, como puede advertirse en la siguiente respuesta:

Cuando dije que carecemos de inscripciones, no pretendi hablar de los antiguos indios mexicanos. Ellos eran sabios; sus jeroglificos llenaban los nú. meros de una completa escritura, y sólo dudará de esto el que fuese tan bárbaro como los que, movidos de un celo indiscreto, arruinaron los magnificos edificios de su grandeza... Si alguno dudare de lo que digo, que me apronte algunas cantidades para hacer excavaciones en Tlatelolco, y ya se admirard de lo que abriga este nuevo Herculano. No distan mucho de mi casa paterna los célebres palacios de Mitla, que aún existen. Por tanto, nadie como yo está tan persuadido de lo que afirmo... Cuando usted dice en orden a que poseímos excelentes artífices en los años inmediatos a la Conquista, es mucha verdad. España nos dio entonces de lo mucho bueno que le sobraba. Parte de los excelentes arquitectos que no se pudieron colocar en la magnifica obra del Escorial, se esparcieron por las Américas, 
aunque la bella forma de [la ciudad de] México es debida al plan de los indios.

Finalmente, Bustamante concluye con una cita elogiosa de Tresguerras, el famoso celayense cuyo nombre empezaba a ser "noticia" en la escasa prensa de la época:

...Sólo sí he admirado dos [inscripciones] públicas formadas en nuestros días. La una está colocada en un almacén de agua en Querétaro. La mano del sabio Tresguerras formó la estatua de Hércules, clavando una serpiente que vomita un torrente de agua. He aquf la inscripción en castellano: Para público adorno y comodidad. El Muy Ilustre Ayuntamiento.

Tan larga cita, 21 convenía para exponer, en sus términos literales, el pensamiento estético, "neoclásico" y "neoazteca" de Bustamante, un lustro antes de que estallara la revolución de Hidalgo. Ahora bien, el embeleso por Tolsá, fue una actitud generalizada en esos años. Un remitido anónimo al mismo Diario de México (anónimo que, por la forma de expresarse, también "huele" a Bustamante), dice que cayó de rodillas al penetrar a la catedral y "verme sorprendido del bello golpe de hermosura y magnificencia que causa la capilla de los plateros", obra tolsiana recién estrenada. $Y$ al éxtasis siguió la siguiente invocación:

Dictanos tus sabios discursos, Fidias valenciano. Tú eres el Vitrubio de nuestros tiempos, el Paladio español, el maestro grande, el arquitecto sabio y el diestro artífice. $10 h$, enquera [sic] hermosa y amada villal ¿cuándo me cansaré de elogiarte?, pues has producido el mejor vástago que han visto las edades, el que nos ha dado ópimos y sazonados frutos, el que, a pesar de algunos fatuos de estos tiempos, poco apreciados, en los venideros, al ver los monumentos indelebles de su exquisito gusto, y trasmitiéndose de padres a hijos el nombre del grande Tolsá, levantarán sus ceñidas frentes y bendecirán al Altísimo. ${ }^{22}$

Tanto se hablaba de la Academia y del "buen gusto" que ella había impuesto, que algún chusco sugirió la idea de fundar también una "Academia del Arte Culinario", pues -argumentaba-, "yo no ballo la razón de no haberse ennoblecido el arte de la cocina como el de la pin-

21 Suman ocho los artículos sobre arte de esta polémica, publicados por el Diario de México, del 16 al 28 de diciembre de 1805, bajo los títulos: "Literatura", "Huma. nidades" $y$ "Bellas Letras".

22 Diario de Mexico, 24 de mayo de 1808. Artículo con el encabezado: "Se nos ha remitido el siguiente papel sobre arquitectura." 
tura, escultura, música y otras; si éstas son útiles, aquél es necesario; las primeras pertenecen más bien al lujo que a la necesidad; el otro al contrario". ${ }^{23}$ Y como todo debía ser pensado, medido, equilibrado, armónico y reglamentado, las creaciones humanas que no se ciñeran a tal receta, debian ser declaradas out; por ejemplo, el pobre arte barroco. No nos extrañe, en consecuencia, que Bustamante, en una serie de artículos en que enumera los males - junto con las posibles solucionesque padece la ciudad, señale éste:

Están a gusto de los más, los colaterales de piedra pequeños, con sólo una hermosa imagen. Quiero que me digan, ¿a qué fin son esos colateralones de madera, tan dorados de arriba abajo, con grave riesgo en un incendio, como se ha visto, sirviendo de escondrijo para ratas y otros bichos inmundos en la morada terrena del rey celestial, o para que un malhechor se oculte, aparte de su exorbitante infructuoso costo en la mayor parte? No debe ser asi, señores. Y se suplica con la atención debida a los ilustrísimos señores obispos y provinciales reverendísimos de las sagradas religiones, no permitan en lo sucesivo se levante colateral de dicho tosco modo, que después todos los desdoran los zaragates o los sacristanes, subiendo y bajando por sus columnas a poner colgajos y encender luces para funciones, con riesgo de sus vidas. $Y$ los que puedan quitarse de esa antigua hechura o minorarse, ejecútese. 24

Así: jejecútesel Por lo que la guerra declarada contra Churriguera, Balbás y tantos ilustres artistas, "pasados de moda", asumió las proporciones de una cruzada general e implacable. No sólo dirigida por arquitectos y escultores, que al fin y al cabo eran los autores de las nuevas obras y los responsables de la estética oficial, sino por la opinión pública pensante, que los empujaba en esa dirección, como se advierte en este significativo texto del oaxaqueño.

El 4 de agosto de 1810 se estrenó, en medio de viva expectación, el nuevo altar mayor de la iglesia de Santo Domingo, encomendado a Tolsá, quien, por supuesto, previamente habfa hecho astillas el antiguo barroco, de 1736 y calificado en su tiempo como "primoroso altar, que a esmeros del arte y retoques del pincel, ofrecía al buen gusto [sic] y a la curiosidad un objeto verdaderamente admirable y digno de aquel insigne y magnífico templo". 25 Ya se ve que el "buen gusto" de 1736

23 Diario de México, 14 de diciembre de 1809. Articulo "Culinaria".

24 Diario de México, 21 de noviembre de 1809. Artículo: "Bueno y con buena intención."

25 Gazeta de México, núm. 105, agosto de 1736. En: Gacetas de México, ed. de Francisco González de Cosio, México, Secretaría de Educación Pública, 1950, t. II. p. $\mathbf{3 5 5}$. 
no coincidía con el de 1810 , porque cada época aboga por su respectivo "buen gusto", que nunca es el mismo que el de la precedente. Y bien, Bustamante echó su cuarto a espadas, publicando en el Diario de México del mismo día 4, una "descripción arquitectónica" del altar tolsiano, en la que a la par que se advierte su fluido estilo periodístico y la claridad con que maneja un vocabulario técnico más o menos acertado, evidencia su intolerante neoclasicismo, al grado de censurar las concesiones ornamentales de la obra, especie de mea culpa del artista valenciano, por lo mucho que fustigaba y destruía las creaciones del barroco. Los nombres de Manuel Tolsá y de José Antonio González Velásquez (este último, Director de Arquitectura de la Academia, citado incorrectamente por Bustamante), surgen de la pluma del oaxaqueño nimbados con los más cálidos elogios, debido a ser, en su opinión, los insignes abanderados del arte nuevo, "del bello gusto" que está de moda, que complace a la generalidad, que remedia los entuertos del "arte viejo" y que a él, en particular, embelesa y extasia. El párrafo alusivo, en un tono tipicamente bustamantino, no tiene desperdicio:

He aquí una nueva prueba del recomendable mérito de don Manuel Tolsá, autor de esta obra. Don Manucl Velásquez [sic], Director de Arquitectura de esta Academia, que murió el día 12 de abril del presente año, y de quien no hemos hecho el correspondiente elogio por falta de datos relativos a su nacimiento y carrera, concluyó varios retablos de mérito que están sin describir, comenzando por el de la parroquia de San Pablo y acabando por el de la iglesia de Jesús María y colaterales menores de la Profesa. Pocos días antes de morir, le supliqué me hiciese una descripción de la bella iglesia de Jesús María, que no había presentado al público por su moderación; convino en formármela, pero la muerte cortó el hilo de su vida, preciosa para las artes... Los templos augustos, los edificios magnificos que se elevan erguidos y brillan en esta capital, hablarán en todos tiempos y dirán a la posteridad: "Nosotros somos obra de la sabiduría y noble atrevimiento de don Antonio Velásquez [sic], plantador del bello gusto en la arquitectura en esta capital; a mi cargo está publicar su gloria."

De este Velásquez, que tanto entusiasma a Bustamante, opina Toussaint que "no fue ninguna lumbrera y dejo pocas obras"; ${ }^{20}$ y el mismo don Carlos no repara en que se contradice, pues fue precisamente Velásquez el autor del remodelamiento de la Plaza Mayor en 1796, que tanto le desagradaba. Pero volviendo a su descripción del altar mayor

26 Arte colonial en México, op. cit., p. 229. 
de Santo Domingo, citemos la objeción principal que le hace Bustamante:

Es cosa lastimosa que se le haya quitado la hermosura a este monumento de buen gusto, poniéndole ramilletes y zarandajas de plata, cuando por si nada necesita, por ser majestuosa, bella y recomendable por sí misma su construcción. Lo mismo se hizo con la iglesia de Jesús María, y esto prueba que los sacristanes tienen muy poca o ninguna idea de la belleza del arte, pues apelan a estos adornos churrigueros, sin los que creen que nada hay bueno. IQué raíces tan profundas no echó el mal gusto con el transcurso de los muchos siglos por cuyo espacio dominó!

Por supuesto que no hay tales "muchos siglos", ni las concesiones al estilo artístico periclitado se debía a la presión de los sacristanes. El sentido de esa "inter-relación" de formas, que no acababa de entender el "moderno" Bustamante, era mucho más profundo; tal y como lo explica, con su habitual agudeza, don Justino Fernández: "Creer que el barroco es pura exaltación del sentimiento es tan equivocado como creer que el clásico es pura exaltación del intelecto; no, no hay pureza que valga; el barroco no puede menos de tener cierta estructura, a menudo clásica, y el clásico no puede menos de estructurarse según los dictados del sentimiento, a menudo barroco." 27 En efecto, a esos "dictados del sentimiento", $\tan$ comunes a la sociedad novohispana de finales del virreinato, se debía que Tolsá y sus colegas "barroquizaran" con frecuencia sus obras neoclásicas. Y que el gusto por el "arte viejo" no habia muerto del todo en 1810 , lo prueba la réplica que a los pocos días de publicado su artículo recibió Bustamante, y que vale la pena conocer:

¿Por qué son zarandajas, señor critico? Yo esperaba la razón toral y nos sale el crítico con el mal gusto de los sacristanes. Vamos al caso, critico. ¿Por qué son zarandajas los ramilletes y adornos que tenía el altar mayor de Santo Domingo? ¿Sabe usted por qué? Porque usted ignora el castellano de esta voz, quiero decir, su genuina significación. La magnificencia del templo no se mide por las coplas inéditas sino por la tradición de la Iglesia, inviolable en todos sus siglos hasta el nuestro. Lea usted la magnificencia del templo de Salomón y alli advertirá usted que aunque no se vea el alabastro del tabernáculo [basta con que] se vea el exceso de las ofrendas y votos de los fieles. ¿Ve usted ese humo espeso que nubla el templo y hace despedir los aromas que se queman en el incensario? ... Pues es un magnifico humo, un humo elocuente, un humo misterioso... Asi es la copia de luces, ramilletes, candeleros, Elores y todo eso que usted llama zarandajas, pues si se omiten,

27 El arte del siglo XIX en México, p. 4. 
falta la majestad de los adornos, sin los cuales... se ve desnuda de las demostraciones con que los fieles adornaron los templos primitivos. 28

No deja de ser interesante esta interpretación que sobre el simbolismo del barroco hace, en 1810, el enojado impugnador de Bustamante. Y es curioso, el año en que los mexicanos se declararían la guerra a muerte para decidir si seguían llamándose "coloniales" o adoptarían el flamante apelativo de "nacionales", en materia estética y por medio de la prensa, también se daba igual debate, entre el espíritu barroco y el espíritu neoclásico, entre el pasado y el futuro, entre lo "antiguo" y lo "moderno". En rigor no se trataba más que del choque dialéctico por definir la esencia del ser de México.

Con la guerra de independencia, Bustamante abandona sus preocu. paciones estéticas. Después de 1821, vuelve a menudo a ellas, como ya hemos visto en algunas páginas de este trabajo. Pero recoger el grueso de sus opiniones sobre la materia, hasta el año de su muerte, es tarea que apenas vamos desbrozando y que, desde luego, no tiene cabida en el presente ensayo. Quede lo anterior como una muestra curiosa e importante de la faceta más ignorada del pasional, romántico y pintoresco y muy mexicanista escritor que fue don Carlos Marla de Bustamante: critico de arte de su tiempo, para satisfacción y ameno placer del nuestro.

28 "Zurra al critico que censuró el adorno del altar mayor del Imperial Convento de Santo Domingo", Diario de México, 17 agosto 1810. 